\title{
Research Article \\ Effect of Composite Action on the Strength of Wood Roofs
}

\author{
Ivan A. Campos Varela, ${ }^{1}$ Walter H. Gerstle, ${ }^{2}$ and Stephen Dwyer ${ }^{3}$ \\ ${ }^{1}$ L.A. Fuess Partners, Dallas, TX 75219, USA \\ ${ }^{2}$ Department of Civil Engineering, University of New Mexico, Albuquerque, NM 87131, USA \\ ${ }^{3}$ Sandia National Laboratories, Albuquerque, NM 87185, USA \\ Correspondence should be addressed to Ivan A. Campos Varela; ia.campos88@gmail.com
}

Received 30 September 2014; Revised 12 February 2015; Accepted 17 February 2015

Academic Editor: Lucio Nobile

Copyright (C) 2015 Ivan A. Campos Varela et al. This is an open access article distributed under the Creative Commons Attribution License, which permits unrestricted use, distribution, and reproduction in any medium, provided the original work is properly cited.

\begin{abstract}
Engineering certification for the installation of solar photovoltaic modules on wood roofs is often denied because existing wood roofs do not meet current building codes. Rather than requiring expensive structural retrofits, we desire to show that many roofs are actually sufficiently strong if the effect of composite action produced by joist-sheathing interaction is considered. In a series of laboratory experiments using a limited number of two-by-four wood joists with and without sheathing panels, conventionally sheathed stud-grade joists, surprisingly, exhibited between $18 \%$ and $63 \%$ higher nominal strength than similar bare joists. To explain this strength increase, a simple model was developed to predict the strengths of the nailed partially composite sections, but the model only justifies a $1.4 \%$ to $3.8 \%$ increase in bending strength of joists with an allowable bending strength of 1000 psi. More testing is indicated to resolve this discrepancy between laboratory results and analytical modeling results. In addition to elucidating nonlinear partial composite behavior of existing roof systems, this paper shows that, with minor changes in roof framing practices, strength increases of $70 \%$ or more are achievable, compared to the strengths of conventionally sheathed joists.
\end{abstract}

\section{Introduction}

Recently, many homeowners have been unable to obtain engineering certification to install solar photovoltaic (PV) modules (estimated to weigh $5 \mathrm{psf}$ ) on their roofs. This is because the code-specified load-carrying capacity of the roof is inadequate to support code-specified design loads. Additionally, with design snow and wind loads having gradually increased over the years, many older houses are out of compliance with current building codes, even without the added load of PV modules. It is hypothesized that, by reconsidering composite sheathing-joist action, these roofs are actually stronger than what current building codes predict, in which the strengthening effect of composite action is ignored.

A typical residential wood roof system usually consists of wood joists or prefabricated wood trusses spaced at 24 inches on center, with plywood or oriented strand board (OSB) sheathing panels nailed to the tops of the joists at 12 inches on center (for joists not on panel edges). The sheathing panels are usually 4 feet by 8 feet in size, with a 1/8 of an inch gap between them, as shown in Figure 1.

Current engineering practice assumes the joist bending strength is not increased by the sheathing, albeit with several factors (like the 15\% repetitive member factor), instead of considering the joist-sheathing assembly to be acting as a system that produces a higher strength perhaps capable of resisting the updated increased minimum design loads and the PV module dead load.

Although other system effects are important, this paper focuses on the interaction between a joist and the discontinuous structural sheathing and the effect this composite behavior has on the strengths of roofs.

Rather than requiring expensive retrofits to existing roofs that appear to be too weak using standard engineering assumptions, it is desirable to reconsider the strength of existing roofs. The purpose of this paper is to determine, by testing and calculation, whether an increase in the strength of the joists can be justified by considering composite 


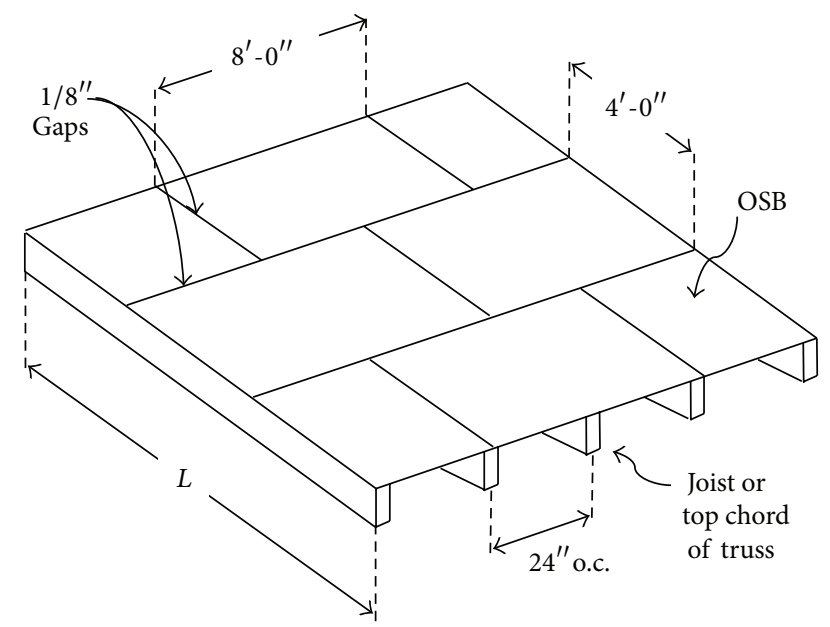

FIgURE 1: Typical roof system.

joist-sheathing action to compensate for the extra weight of the PV panels.

\section{Literature Review}

When nailed at 12 inches on center, full composite action (FCA) is not achieved between the sheathing and the joist because of the flexibility of the nails and the presence of gaps between the sheathing panels, thus developing only partial composite action (PCA). The shear flow generated at the interface between joist and sheathing is influenced by the relationship between shear force and shear deformation of a nail. If the shear force being carried by the nails is below their proportional limit, then the behavior of the interface will be linear and linear partial composite action (LPCA) is developed; on the other hand, if this shear force is higher than the proportional limit, then the behavior of the interface is nonlinear and nonlinear partial composite action (NPCA) is developed.

Previous studies, described in this section, have examined system effects like composite action, load sharing, and stiffness variability, among others, many of which have been recognized to improve the overall performance of roof and floor assemblies.

Assuming LPCA conditions, Kuenzi and Wilkinson [2] developed deflection and strength equations for two specific loading conditions: four-point bending and distributed load for simply supported beams with continuous sheathing.

McCutcheon modified the LPCA deflection equations of Kuenzi and Wilkinson and developed a method for predicting the stiffness of wood-joist floor systems assuming LPCA, with a layer of sheathing on only one side of the joist [3] and on both sides of the joist [4]. McCutcheon also defined the effective stiffness of the partial composite section (to be utilized in the elementary beam deflection formulas).

McCutcheon's analytical method was utilized in further research by Wolfe and McCarthy [5] to calculate an increase in strength. Neglecting connection flexibility, this increase in strength was calculated as the ratio of an effective section modulus (from McCutcheon's model) to the section modulus of a bare joist. Results were presented for glued-andnailed joists only, while only-nailed joists calculations were not performed because they were said (with little scientific justification) to produce no increase in strength due to inconsistencies in experimental results of some assemblies.

Wolfe and LaBissoniere [6] also tested three wood-truss roof assemblies and concluded that at failure loads the nailed connections between the sheathing and the top chord of the trusses were stressed beyond the elastic limit and said that NPCA has little effect in reducing the tensile stresses in the top chord due to bending moments and thus composite action should be ignored. This conclusion is not scientifically justified, and it is reconsidered in this paper.

Several computer programs have also been developed to take into account other system effects, like load sharing and two-way action, for floors and framing walls [7-11]. Although the existence of these additional system effects is recognized, they are not the main topic of this research.

Recognizing load sharing by joists, the repetitive member factor $\left(C_{r}\right)$ was established by the National Design Specification for Wood Construction [12] and permits a 15\% increase in the allowable joist bending stress value using the ASD method and a factor of 1.15 increase in the nominal strength using the LRFD method, when the roof of floor assemblies meets certain requirements.

Also, increases of up to $50 \%$ in the bending strength of wall framing studs have been established due to system effects and composite action based on previous research by Polensek [8] and Douglas and Line [13] However, these factors have not been recognized yet by the NDS, and the increases where composite action is taken into account are only for wall studs with two layers of sheathing with specific characteristics not applicable for roof joists or trusses.

Rosowsky and Yu [14] developed another approach for wall framing, although also suitable for repetitive member systems. They proposed a different factor for each of the system effects they studied (LPCA, system size, postyield behavior, and load sharing), instead of having just one single repetitive member factor, $C_{r}$, as provided by the NDS. The proposed factor by Rosowsky and Yu for PCA is given by (1) as

$$
K_{\mathrm{PCA}}=\frac{6(\mathrm{EI}) h}{6\left(\mathrm{EI}_{j}\right) h+h_{j}\left[\mathrm{EI}-\left(\mathrm{EI}_{j}+\mathrm{EI}_{s}\right)\right]},
$$

where $\mathrm{EI}_{j}$ is the bending stiffness of the joist, $\mathrm{EI}_{s}$ is the bending stiffness of the sheathing, EI is the effective bending stiffness of the T-beam (using McCutcheon's method), $h_{j}$ is the depth of the bare joist, and $h$ is the internal moment arm. As explained further below, this method cannot be entirely correct because it does not account for the nonlinearity of the connection.

On the other hand, an approach to achieve FCA was utilized by Rancourt [15] using OSB sheathing on the top and bottom of I-joist with glued joints, obtaining up to a $124 \%$ increase in strength and a $115 \%$ increase in stiffness compared to the bare I-joist. This was achieved using continuous OSB sheathing (up to 16 feet long), developing FCA of the panel. 
However, FCA behavior cannot be assumed for typically sheathed (nailed) roof systems.

It is important to note that in all of the previous models where McCutcheon's approach was utilized to calculate an increase in strength in the T-beam with LPCA two effects were not considered: the nonlinear behavior of the nails and the effect of gaps in sheathing. Recall that (1) is based on McCutcheon's approach, which only considers the effect of the gaps when calculating the initial stiffness (and not the strength) of the T-beam.

A new formulation to determine bending strength, provided in this paper, is needed to take into account nonlinear behavior of the nails as well as the effect of gaps in the sheathing.

\section{Exploratory Laboratory Experiments}

Several sets of exploratory laboratory tests were conducted, described next.

\subsection{Set 1: Preliminary Exploratory Tests-Three Assemblies, One Bare, One Nailed, and One Glued-and-Nailed}

3.1.1. Test Setup. As a scoping exercise, three wood joist and structural sheathing assemblies similar to those commonly utilized in top chords of trusses or in joists in roof systems were loaded to failure in a four-point bending test. All of the assemblies consisted of three simply supported $2 \times 4$ $\left(1.5^{\prime \prime} \times 3.5^{\prime \prime}\right.$ actual dimensions $) \times 8^{\prime}-0^{\prime \prime}$ Hem-Fir joists visually graded as studs by the Western Wood Products Association (WWPA), spaced at 24 inches on center. The OSB's strong axis was oriented perpendicular to the longitudinal axes of the joists. Two of the three-joist assemblies had $4^{\prime}-0^{\prime \prime} \times 4^{\prime}$ $0^{\prime \prime} \times 7 / 16^{\prime \prime}$ thick OSB panels attached to the top of the joists, as shown in Figure 2, leaving a $1 / 8^{\prime \prime}$ gap at midspan. One assembly was constructed with nailed joints and the other with glued-and-nailed joints ( $8 \mathrm{~d}$ nails at $11.5^{\prime \prime}$ spacing, $\mathrm{PL}$ 400 Floor and Deck semistructural adhesive) to connect the OSB panels to the joists. As a control, the third of assembly consisted of three joists without sheathing. The support and loading geometry and the resulting cracking patterns for the three tests are shown in Figure 3. The load was applied using displacement control at a rate of $0.10 \mathrm{in} / \mathrm{min}$.

3.1.2. Results. In all of the tested assemblies, only one of the three joists failed, perhaps because the assemblies were loaded under displacement control. The first joist to fail was always on one side of the assembly. Figure 3 also shows the locations of the cracks that initiated failure in each failed joist (in each case, initiated at the location of a knot on the tensile side of the joist) and their approximate trajectories.

As shown in Figure 4, a load capacity increase of $73.4 \%$ for the glued-and-nailed assembly and a 34.5\% increase for the nailed-only assembly, relative to the bare joist assembly, indicated an increased strength for the composite assemblies. Nonetheless, this increase in strength could be due to the high variability in the bending strengths of the joists themselves, and thus a larger set of experiments was next performed to determine whether this behavior was repeatable or not.

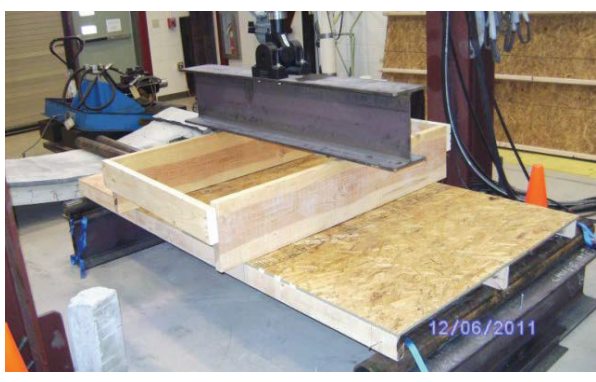

FIgURE 2: Photograph of test setup.
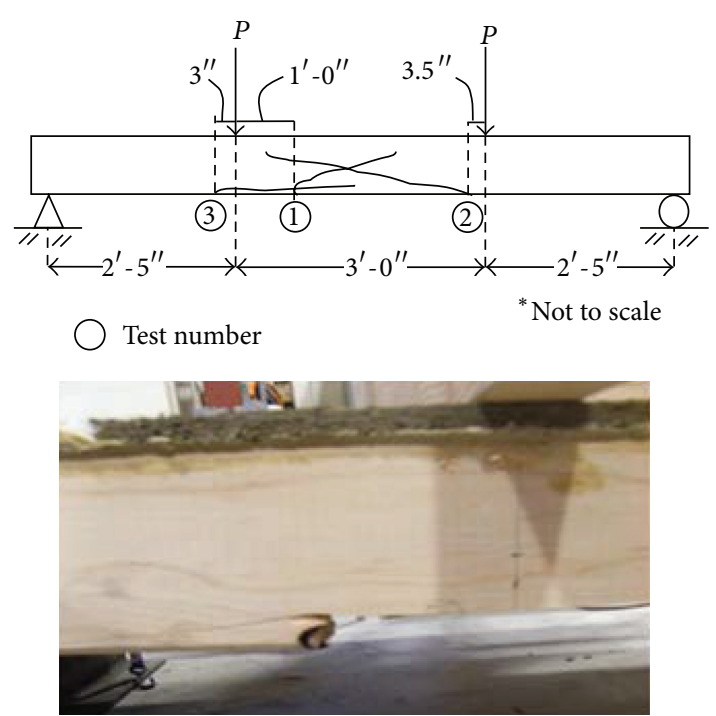

FIGURE 3: Sketch of cracks in tested joists, and photo of typical crack initiation at knot on tensile face of joist.

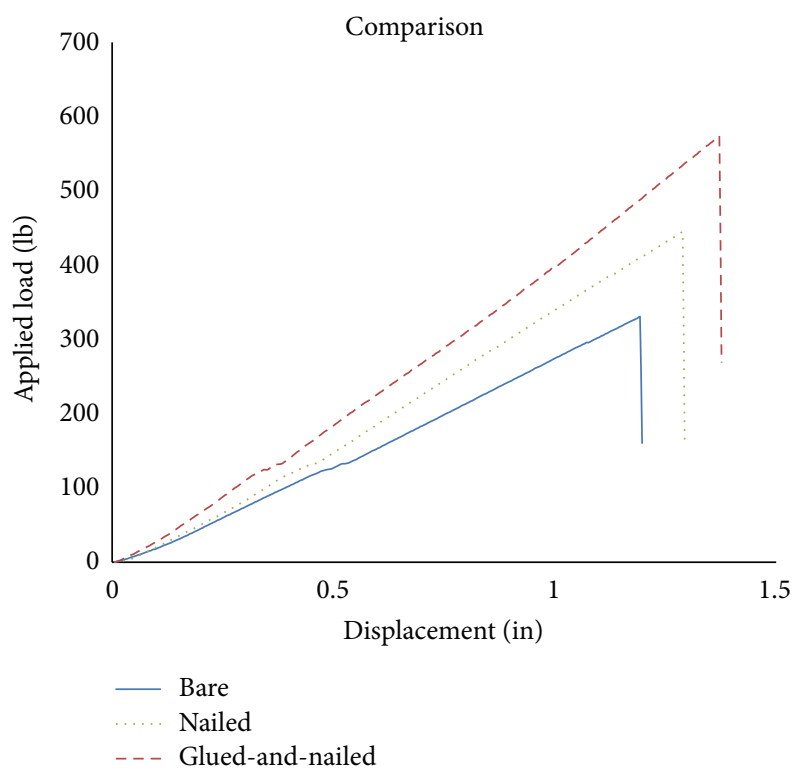

FIGURE 4: Comparison between loading-displacement relations of preliminary tests. 


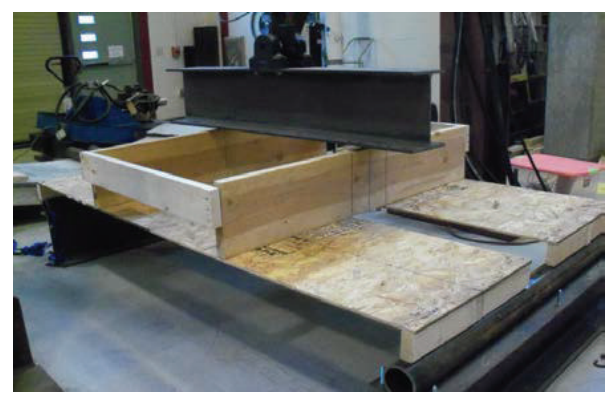

FIGURE 5: Second set test setup.

\subsection{Set 2: Two Bare Joists, Three Nailed and Three Glued-and- Nailed Composite Joists}

3.2.1. Test Setup. A set of eight flexural tests was performed to provide more data to better understand the results obtained in the preliminary exploratory tests. These specimens were slightly modified to avoid load sharing effects and to isolate the effects of composite action between the joist and the OSB. Now, each specimen consisted of only one $2 \times 4$ joist $\times 8^{\prime}-0^{\prime \prime}$ (also visually graded as stud) with two $2^{\prime}-0^{\prime \prime} \times 4^{\prime}-0^{\prime \prime}, 7 / 16^{\prime \prime}$ thick OSB panels on the top, to form a T-beam (with a 24inch-wide flange and the same $1 / 8^{\prime \prime}$ gap at midspan), as shown in Figure 5.

Two bare joists and six composite joists (three with a nailed joint only and three with nailed-and-glued joint) from a second batch of joists were carefully selected, with variable locations of knots along their spans, to test the hypothesis that the location of the weakest point in the joist with respect to the location of the gap in the sheathing plays a key role in increasing the bending strength of the joist due to PCA. The T-beams and the bare joists were loaded to failure with the same loading conditions as in the preliminary tests, as shown in Figure 5.

3.2.2. Results. In this set of experiments, two out of three nailed-only T-beams failed at a location of a knot in the constant-moment region, while in the third case no knot existed in the constant-moment region and failure was initiated at the bottom of the joist three inches away from the gap, resulting in a higher strength than in the case of joists with knots in the constant-moment region. This behavior agrees with the hypothesis that if no knots are present in the constant-moment region, then failure in the joist should occur near the location of the gap, where stresses are highest. The load-displacement relation for all specimens demonstrated essentially linear behavior up to failure, as shown in Figure 6, which shows that an increase in stiffness (as the rigidity of the connection at the interface increases) does not necessarily mean an increase in strength. Also, in contrast to the results of the previous set of experiments, the strengths of the glued-and-nailed T-beams were not always higher than the nailed-only T-beams, as shown in Figure 6, although all six of the sheathed joists were stronger than the two bare joists. This variability in strength is attributed to

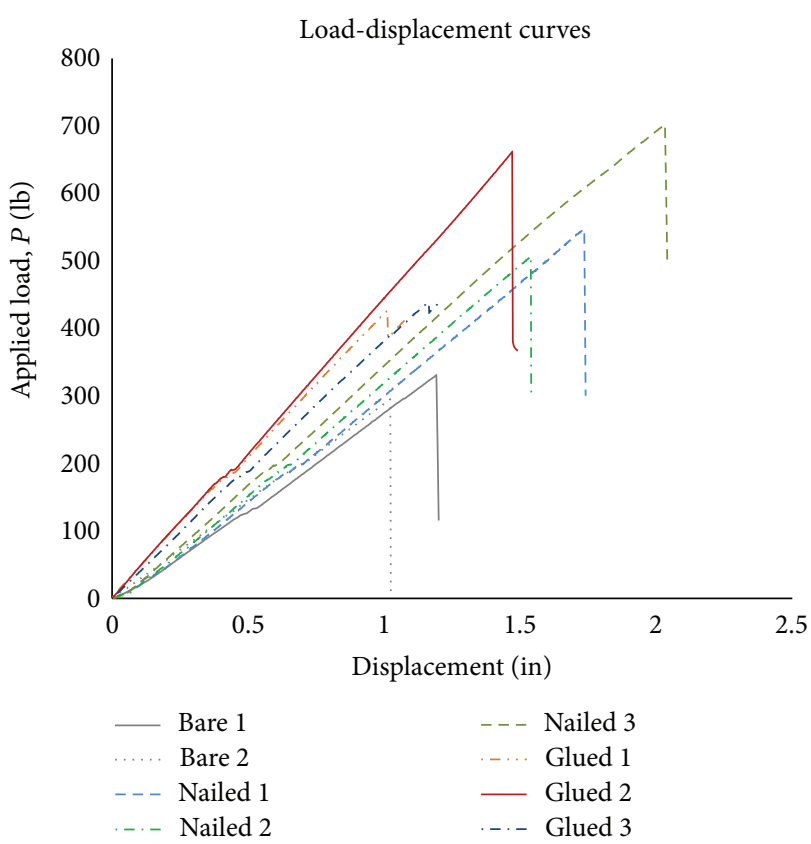

FIGURE 6: Load-displacement relations for tested specimens.

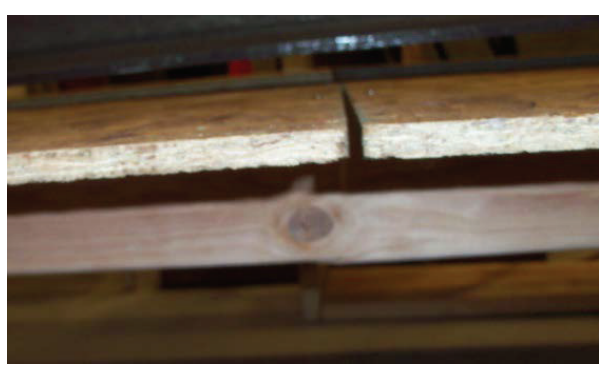

FIGURE 7: Knot at almost the same location as gap.

the differing positions and sizes of the strength-controlling knots, among other factors.

Figure 7 shows a 1.5-inch knot at less than 2 inches from the gap location in a glued-and-nailed T-beam, resulting in a much lower strength than a nailed-only T-beam. Note that a knot located directly below the gap would be the worst case scenario in achieving any PCA in the T-beam as the flexural stresses at the bottom of the T-beam at this location along the joist are highest. Also note that the probability of having the weakest knot close to or directly below the location of the gap is low, and hence a statistical increase in the strength of the sheathed joist might be expected.

\subsection{Set 3: Nearly Identical Joists with and without Sheathing}

3.3.1. Test Setup. Next, three nominal $4 \times 4\left(3.5^{\prime \prime} \times 3.5^{\prime \prime}\right) \times$ $8^{\prime}-0^{\prime \prime}$ Douglas-Fir joists visually graded as number 1 were selected carefully, so that knots along the span would go as straight and as perpendicular as possible across a transverse section of the joist. The purpose was to cut the $4 \times 4$ joists into two $2 \times 4$ nominal joists, to produce the minimum difference 

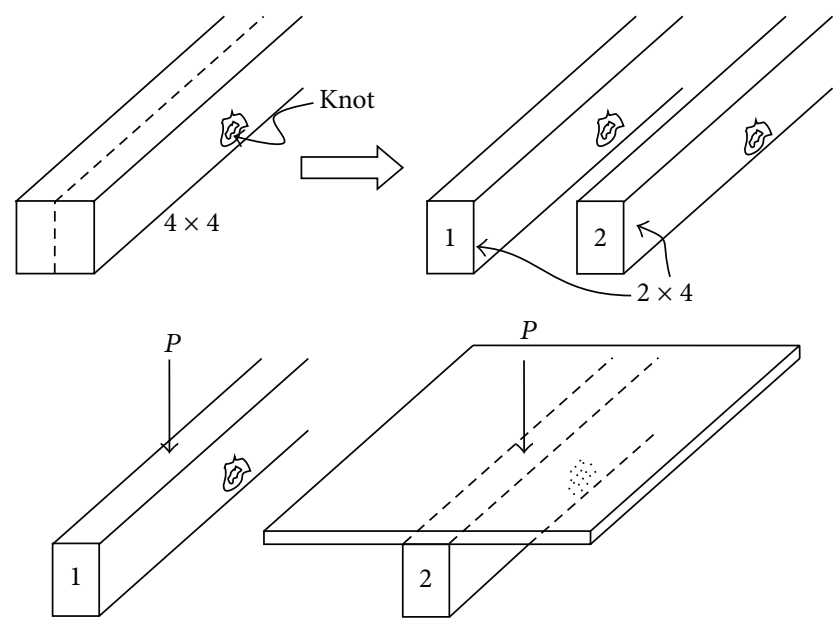

FIGURE 8: Schematic of the procedure for producing twin joists.

in strength, because both joists have nearly identical properties.

A four-point bending test was again utilized but with a longer $4^{\prime}-10.5^{\prime \prime}$ long constant-moment region. Each of the two $2 \times 4$ joists cut from a single $4 \times 4$ joist was tested separately. As a control, the first $2 \times 4$ joist was tested as a bare joist to obtain the "bare joist strength," while the second $2 \times 4$ joist was tested as the web of a T-beam, as shown in Figure 8, using again two $2^{\prime}-0^{\prime \prime} \times 4^{\prime}-0^{\prime \prime} \times 7 / 16^{\prime \prime}$ thick OSB panels and leaving a gap at midspan to obtain the "T-beam strength."

This procedure was designed to illustrate the effect of PCA upon stiffness and strength using two (almost) identical joists. To produce clear behavior, it was decided to glue and nail the interface only between the point loads and the supports of the joist, forcing the slip to occur only at the nails within the constant-moment region (closest to the location of the $1 / 8^{\prime \prime}$-wide gap). A dial gage was attached to the top of the OSB to measure the gap closure at midspan when the Tbeams were loaded.

The bare joist was loaded to failure first. Then the composite T-beam was loaded to the load at which the bare joist had failed and the gap opening was measured. Subsequently, the composite T-beam was loaded to failure. The failure loads, $P$, for all the six of the tested specimens, are shown in Figure 9.

3.3.2. Results. As shown in Figure 9, for each pair of $2 \times 4$ joists, the composite joist was stronger than its noncomposite twin. The load-displacement relations for the twin $2 \times 4$ joists from test number 1 are shown in Figure 10. An increase in stiffness as well as in strength is evident for the Tbeam, compared to the bare joist. The readings from the dial gage at the location of the gap showed that the gap had completely closed when the T-beam reached its bending strength. This closure in the gap means that some continuity of the top flange was present and the OSB began carrying higher compressive forces and hence a larger percentage of the total external moment. Note that in all of the previous experiments (with joists with a lower structural grade)

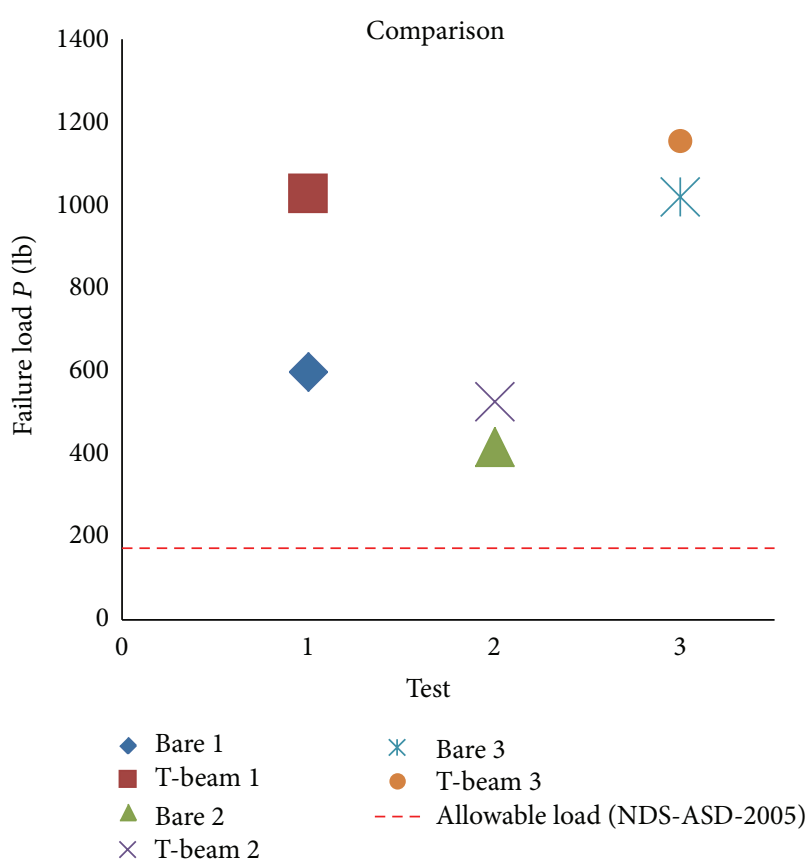

Figure 9: Failure load comparison between specimens.

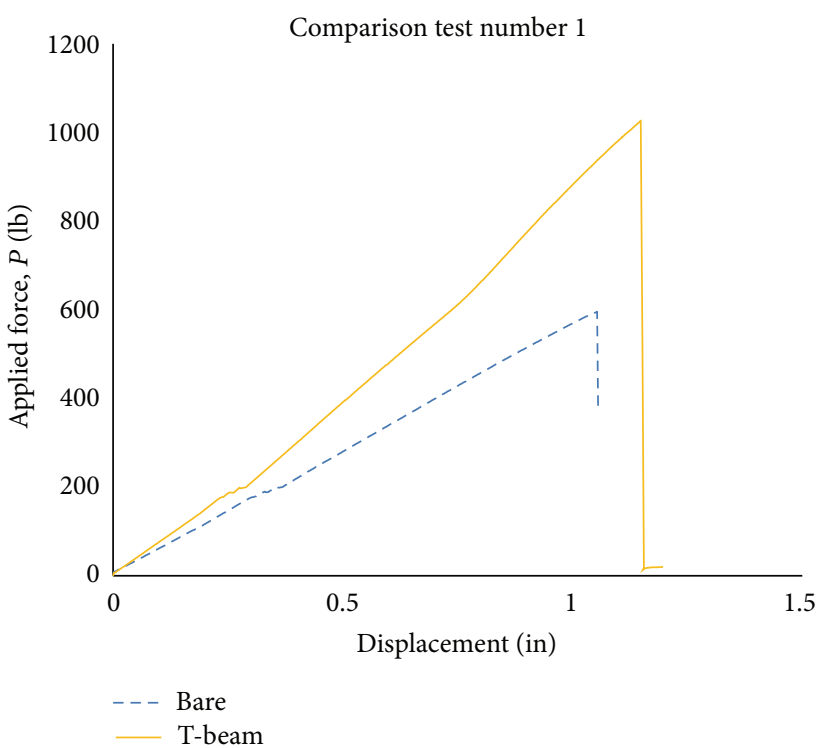

Figure 10: Load-displacement relations for test number 1.

the joists failed before the gap could close. The higher the bending strength of the bare joist is, the more likely the $1 / 8^{\prime \prime}$ gap is going to close completely, as the T-beam will have a greater curvature and a greater slip in the nails. The failure of both the bare joist and the T-beam occurred at the same knot in the constant-moment region.

In tests number 2 and number 3 the initial gap width was increased to $3 / 8^{\prime \prime}$ to prevent gap closure prior to failure. The T-beam from test number 2 registered a total slip of 0.050 inches on each side of the gap at the failure load of the bare joist, while test number 3 registered a slip of 0.129 inches on 
each side of the gap (the $1 / 8^{\prime \prime}$ gap did not close at these slips). Note, as shown in Figure 9, that the strength increase in tests number 2 and number 3 , where the gap did not close, is lower than in the previous tests from Set 1 , where lower-strength studs were utilized.

3.4. Set 4: Load-Displacement Properties of Nailed Joint. Several researchers have tested joist-to-sheathing connections with different specimen configurations and parameters $[1,16-$ 18]. Mi [1] tested ten specimens of spruce pine fir (SPF), connected to $7 / 16^{\prime \prime}$ thick OSB panels with $8 \mathrm{~d}$ nails, developing a multilinear model for the shear load-shear displacement relation based on his test results. Mi's test setup was utilized in this research at constant moisture content conditions, altering only the species of the lumber (Douglas-Fir with almost the same specific gravity as SPF) and loading the specimen in compression rather than in tension. A comparison between the resulting load-displacement relations from the test and the multilinear model developed by $\mathrm{Mi}$, for one nail, is shown in Figure 11. As shown in this figure, the newly obtained relation follows very closely the relation developed by Mi.

3.5. Conclusions of Exploratory Laboratory Experiments. According to the results of all of the flexure tests, there appears to be an increase in the strength of the joist when OSB panels are attached, even if only nailed, and with gaps between panels. A possible explanation for this strength increase is that wood has highly variable bending strength along the length of the joist, mainly depending upon the locations and the sizes of knots (some other effects like slope of grain and moisture content may also have an effect), which are weak points. Thus, if the weakest knot which initiates failure is not located near the location of the gap between panels, this knot will experience a lowered stress due to PCA. Of course, knot size and location with respect to gap location between panels is random, and thus statistics should be brought to bear on the problem.

\section{Analytical and Numerical Analyses}

A simple model to evaluate the increase in strength of the joist due to composite action was developed and is described next.

Consider the T-beam shown in Figure 12, which is similar to those in the experiments of the previous section. As shown in Figure 12(a), the T-beam is loaded to produce constant internal moment, with equal and opposite moments applied at its ends. Nonetheless, shear flow is generated at the interface between the two members of the T-beam because of the changing axial force being carried along the length of the flange. The resultant axial force within the flange is equal to zero at the panel ends, due to the gap, as shown in Figure 13.

When the T-beam section is flexurally loaded, because of the flexibility of the nails, shear slip occurs between the web and the flange, and the two end nails in each OSB panel are subjected to the largest slips, being the first subject to nonlinear behavior, according to their shear forcedeformation relation. Simultaneously, the slips at the interior nails are smaller and can behave either linearly or nonlinearly, according to the imposed shear deformation due to bending.

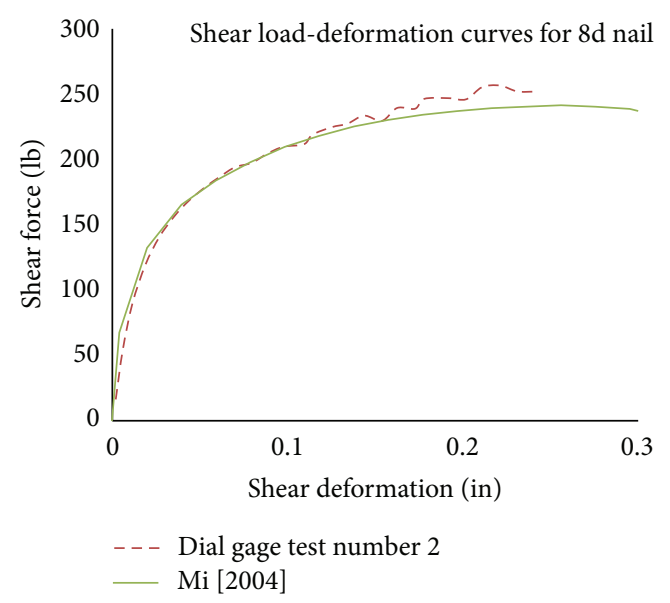

FIGURE 11: Shear load-deformation of one nail, comparison laboratory test, $\mathrm{Mi}[1]$.

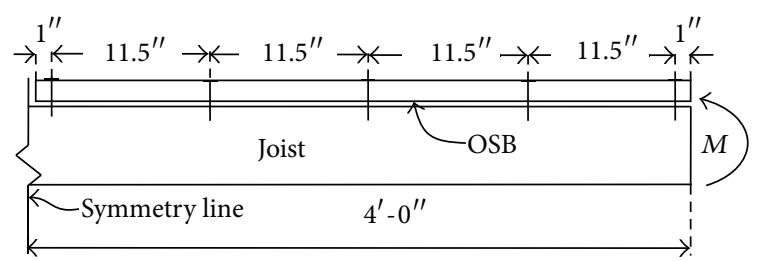

(a)

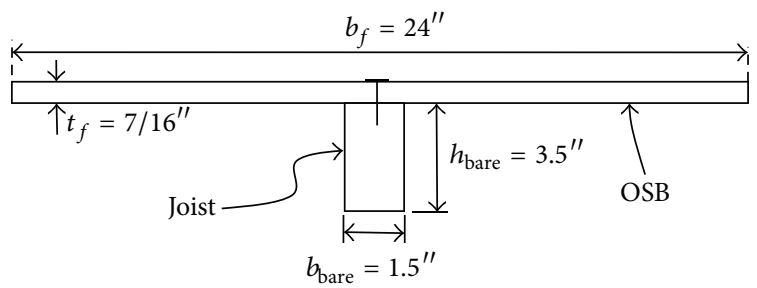

(b)

FIGURE 12: Longitudinal and transverse view of composite T-beam.

To simplify the analysis for obtaining the force that each nail transfers to the flange when the T-beam is subjected to flexure, the nails are assumed to be flexible in shear, and the flange is considered to be comparatively axially infinitely stiff. Hence, the slip of the end nails is calculated as the bending deformation of the top fiber of the joist, with respect to the panel midpoint, as indicated in Figure 14.

In the following, assume the joist and the sheathing are axially infinitely stiff, and assume the T-beam is under constant moment, $M_{f}$, as shown in Figure 14(a). From the basic kinematic considerations, the slip at each nail is obtained as

$$
\Delta_{\text {nail }_{i}}=\frac{M_{f} y L_{i}}{E_{j} I_{b}}
$$

where $\Delta_{\text {nail }_{i}}$ is the slip between nail $i$ and the OSB panel, as shown in Figure 14(b), $L_{i}$ is the horizontal distance between nail $i$ and the midpoint of the OSB panel, $y$ is the distance from the neutral axis of the bare joist to the interface between 


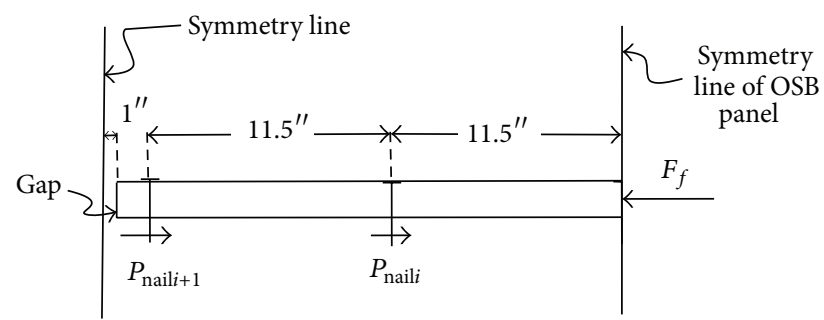

FIGURE 13: Free-body diagram of the OSB panel.

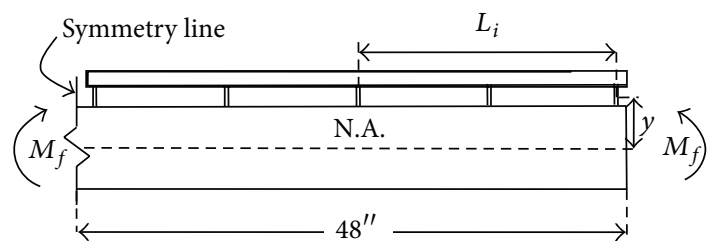

(a)

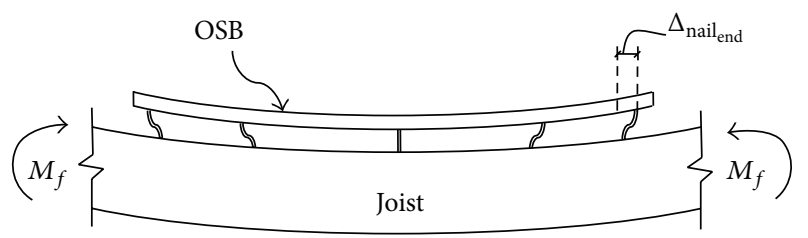

(b)

FIGURE 14: (a) Joist/sheathing model; (b) deformed shape of T-beam.

web and flange, $E_{j}$ is the modulus of elasticity of the bare joist, and $I_{b}$ is the moment of inertia of the bare joist.

If the slip at each nail for a given external moment is known, the shear force being transferred to the flange can be obtained from the load-displacement relation of the nailed joint. Load-displacement relations for various joint patterns have been modeled to evaluate the shear force at a specific slip accounting for the nonlinear behavior of the nails [1618]. However, for ease of analysis, an exponential equation is utilized to fit the curve obtained from the experiments (as shown in Figure 15) and is derived as

$$
P_{\text {nail }_{i}}=a\left(1-e^{\left(-\beta \Delta_{\text {nail }_{i}}-\alpha \Delta_{\text {nail }_{i}}\right)}\right),
$$

where $a=232 \mathrm{lb}, \beta=20$, and $\alpha=30$.

Also as shown in Figure 15, the assumption of the flange being axially infinitely stiff is reasonable, as the maximum shear force that each nail can transfer to the flange is low, and thus the axial deformation of the flange is negligible.

The analysis of the joist, considering the effect of these nail forces acting at its top, can be separated in two load cases, using the principle of superposition, as shown in the freebody diagrams in Figure 16, described as follows.

At section A-A' (far from the gap), if only the forces produced by the nails are considered, a moment opposite to the moment caused by the external loading is produced, generating compression stress at the bottom of the T-beam, as shown in Figure 17(a). Hence, when superimposing the moment produced by the external loading, a tensile stress

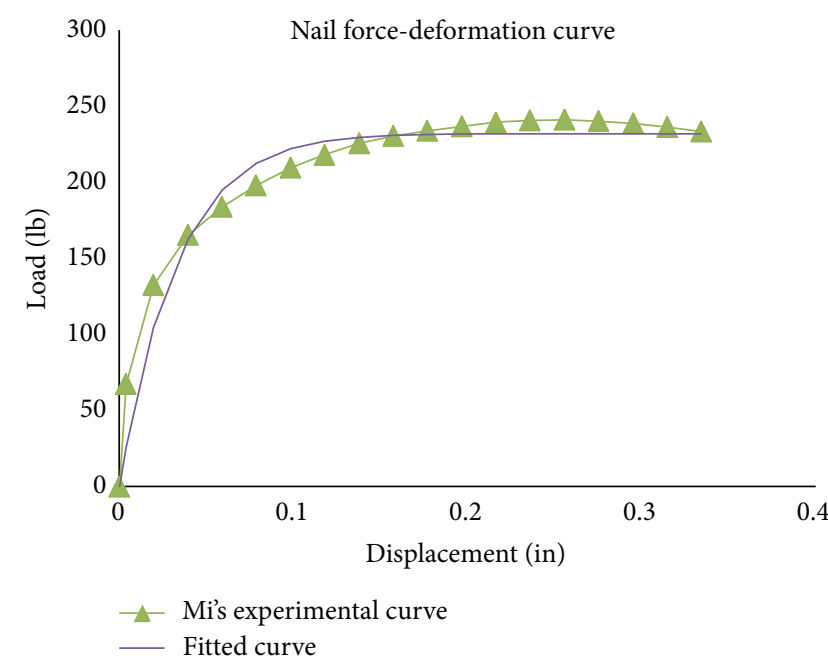

FIGURE 15: Fitted shear force-deformation curve for a single nail.

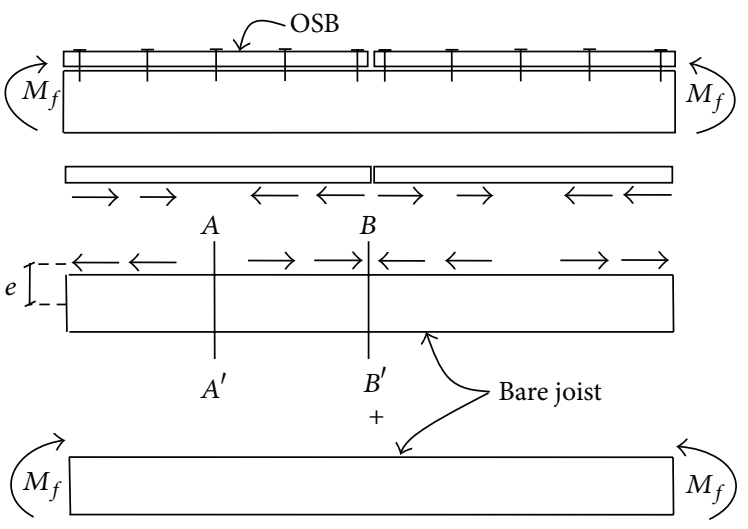

FIGURE 16: Free-body diagram and superposition of forces acting on the joist.

reduction is obtained at the bottom of the joist, as shown in Figure 17(b). This reduced tensile stress (far from the location of the gap), $\sigma_{\text {Tbot }}$, is given as

$$
\sigma_{\text {Tbot }}=\frac{M_{f}}{S_{b}}-f_{b_{\text {nail }}},
$$

where $M_{f}$ is the applied external bending moment, $S_{b}$ is the section modulus of the bare joist,

$$
\begin{gathered}
f_{b \text { nail }}=\frac{\sum_{i=1}^{n} P_{\text {nail }_{i} e}}{S_{b}}-\frac{\sum_{i=1}^{n} P_{\text {nail }_{i}}}{A_{b}}, \\
n=\frac{(N-1)}{2},
\end{gathered}
$$

$N$ is the number of nails per OSB panel, $P_{\text {nail }}$ is the force carried by nail $i, e$ is the moment arm, and $A_{b}$ is the bare joist cross-sectional area.

According to classical Euler-Bernoulli beam theory, this reduction in stress is lost at the location of the gap (section $B-B^{\prime}$ in Figure 16) because of the equal and opposite forces of 

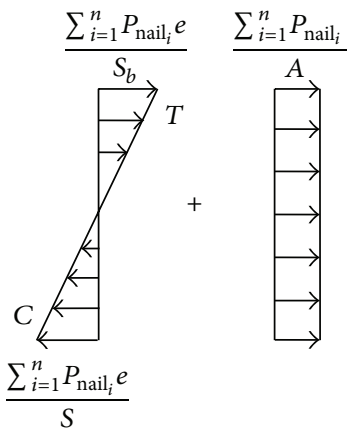

(a)

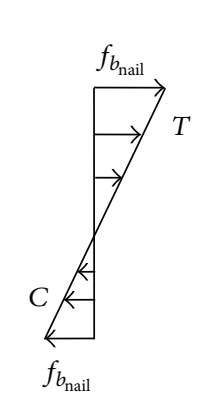

Stress in joist due to nail

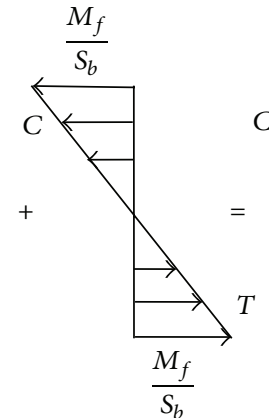

Stress due to applied moment

(b)

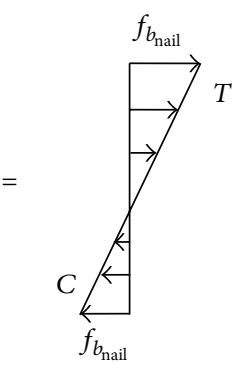

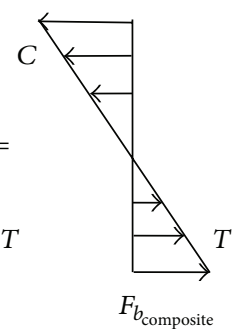

Reduced tensile stress $\sigma_{\text {Tbot }}$
FIGURE 17: Joist stress distribution due to nail forces.

the nails acting on each OSB panel, meaning that the stress at this section would be equal to that from a bare joist analysis. Nonetheless, a linear elastic finite element analysis (FEA) of the pair of forces due to nails acting at the location of the gap was performed. A very fine mesh of plane stress elements with isotropic material was utilized (producing mesh-independent results) to model stress distribution in the joist due to a pair of nails, as shown in Figure 18. Several analyses were performed, varying the distance $s$ (defined as the distance between the end nail in the OSB panel and the center line of the gap, as also shown in Figure 18) and the depth of the joist, $d$, obtaining the tensile stress at the bottom of the joist at the location of the gap. This tensile stress was plotted as a function of the $s / d$ ratio, as shown in Figure 19, where the local effects that the pair of nails cause at the bottom of the joist can be observed. This curve also shows that the magnitude of tensile stress converges to the Euler-Bernoulli solution as the $s / d$ ratio increases beyond one (due to Saint-Venant's principle), to

$$
\sigma_{\text {Tlocal }}=\frac{2 P_{\text {nail }}}{A_{b}} .
$$

If just the end nails in the OSB panel are considered, as shown in Figure 18, and the $s / d$ ratio is higher than one, then there are no local effects due to the nails, as the nail forces counteract each other. However, if the $s / d$ ratio is lower than one, then local effects are present, and the stress at the bottom of the joist at the gap location due to near and far end nails

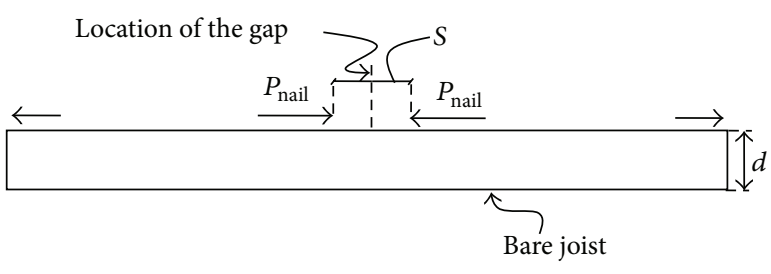

FIGURE 18: Nail forces acting at the location of the gap.

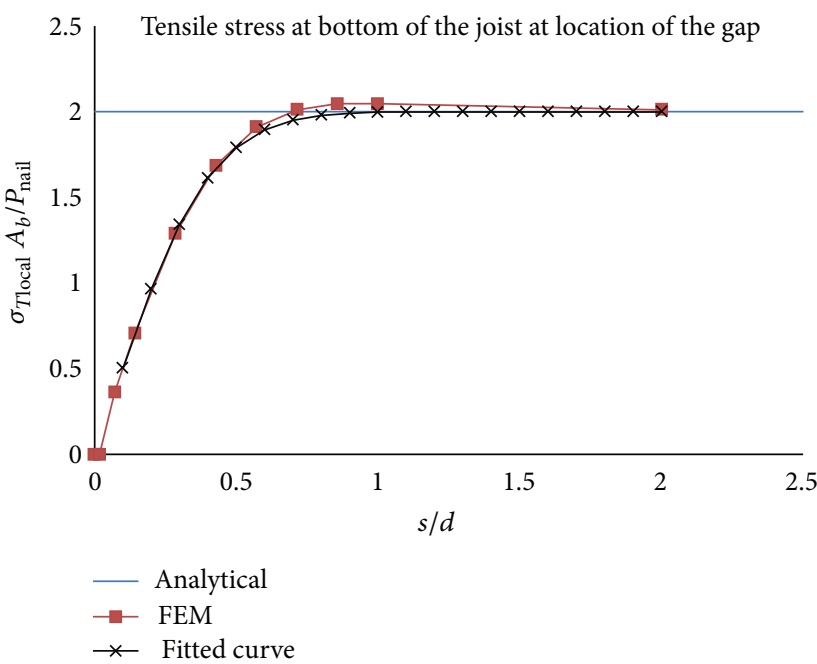

FIGURE 19: Tensile stress at bottom of the joist at the location of the gap due to local effects of closest nail pair.

are no longer equal, resulting in a small compressive stress at the bottom of the joist. This means that even at the location of the gap there will be a small reduction in tensile stress when the external moment is superimposed. The magnitude of the local effects is quantified by fitting the curve shown in Figure 19 with the exponential equation

$$
\frac{\sigma_{\text {Tlocal }} A}{P_{\text {nail }}}=a\left(1-e^{\left(-\beta \Delta_{\text {nail }_{i}}-\alpha \Delta_{\text {nail }_{i}}\right)}\right),
$$

where $a=2, \beta=-2.5$, and $\alpha=4$.

The reduced tensile stress at the location of the gap is derived as

$$
\sigma_{\text {Tbot }_{\text {gap }}}=\frac{M_{\text {tot }}}{S_{\text {bare }}}-f_{b_{\text {nail }} \text { gap }},
$$

where

$$
f_{b_{\text {nailgap }}}=\left(2-\frac{\sigma_{T \text { local }} A}{P_{\text {nail }}}\right) \frac{P_{\text {nail }}}{A} .
$$

Equations (2), (3), (4), (7), and (8) are utilized in an iterative process that takes into account the nonlinearity of the nailed joint and the local effects at the bottom of the joist produced by the nails. This process calculates the change in the nominal moment of the T-beam in each iteration due to the nail forces, until it converges to the ultimate bending strength, obtaining the increase in strength due to NPCA 


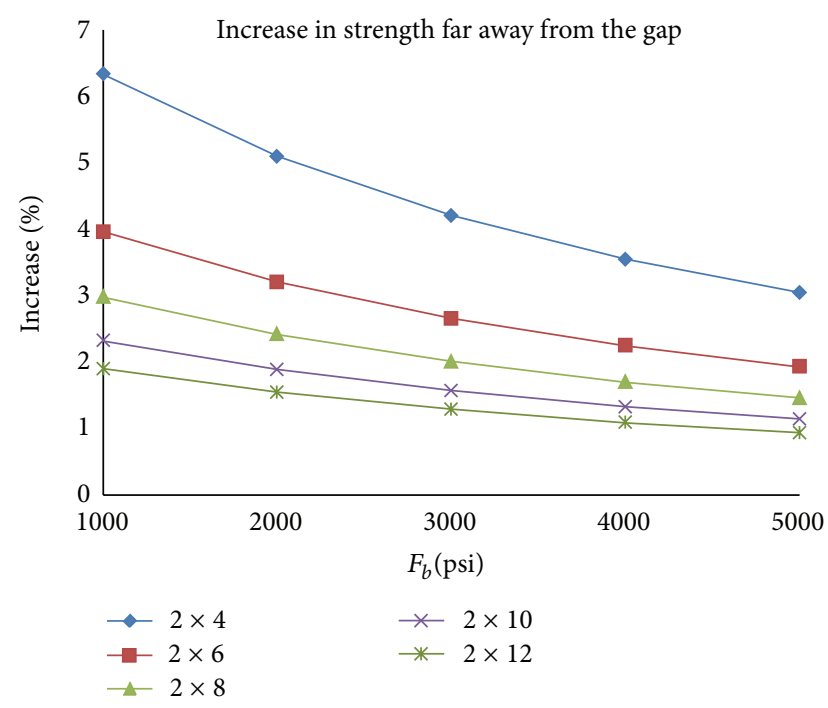

FIGURE 20: Increase in strength as a function of ultimate strength far from gap.

(it only takes three to four iterations to converge to the solution, as the increase in the nominal moment is small). This process is performed at the location of the gap and far from the gap, resulting in the relations shown in Figures 20 and 21 for common dimension lumber. As shown in Figure 21, the increases in strength at the location of the gap can be negligible if no other parameters like the size and location of knots along the span of the joist are taken into consideration. If the weakest knot that initiates the first crack in the joist is far from the location of the gap, it will experience a lowered stress due to composite action, increasing the strength of the bare joist. Nonetheless, this weakest knot might also be near or at the location of the gap, and the T-beam would still manifest slightly higher strength than the bare joist (because of the local effect of the nail forces). However, the location of knots in the joist is random and statistics must be brought to bear on the problem. For simplicity, it is assumed that the total strength increase is the average between the strength predicted for a knot far from the gap (as shown in Figure 20) and the strength predicted for a knot close to the gap (as shown in Figure 21). These averaged strength increases are shown in Table 1 . Table 1 shows that, for $F_{b}$ of the joist of 1000 PSI, the analytically predicted strength increase of sheathed two-by-fours due to NPCA is $3.87 \%$, and the analytically predicted strength increase of sheathed two-by-twelve's due to NPCA is only $1.42 \%$. While there is a strength increase predicted by our analytical model, it is a lot lower than what was observed in the laboratory testing program.

4.1. Conclusions. The laboratory experiments performed have shown an increase in the bending strength of the joists due to the attached OSB panels, even when the panels are only nailed (and not glued) to the joists and when there are gaps between the panels. This behavior was observed in all of the tests, although a high variation in the bending strengths of the tested joists was obtained (due to the variability in

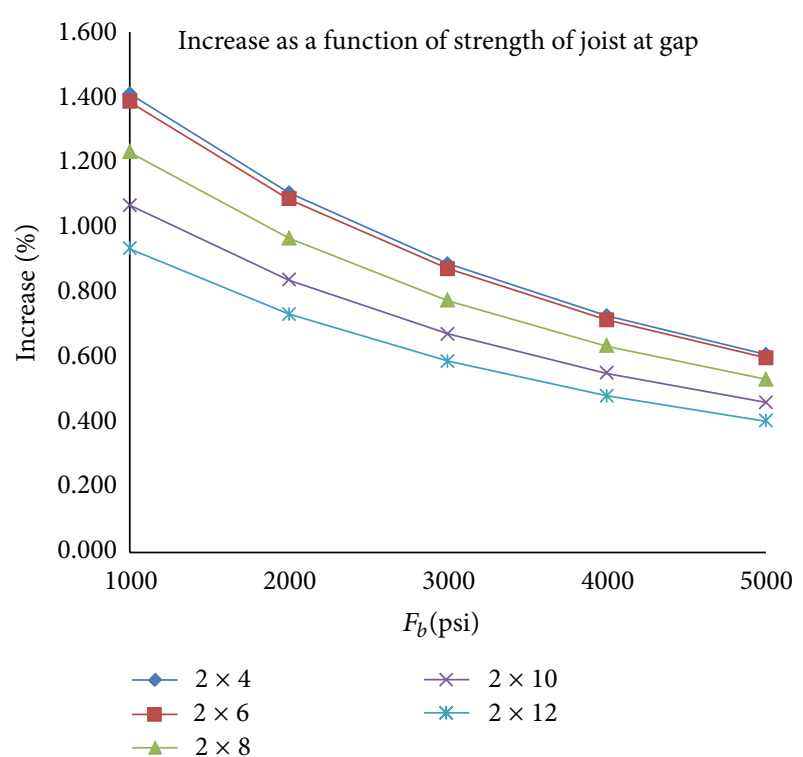

FIGURE 21: Increase in strength as a function of ultimate strength at the location of the gap.

TABLE 1: Analytically predicted average strength increase due to NPCA as a function of ultimate strength of the joist.

\begin{tabular}{lrrrrc}
\hline \multicolumn{5}{c}{ Analytically predicted average strength increase (\%) } \\
$F_{b}(\mathrm{psi})$ & $2^{\prime \prime} \times 4^{\prime \prime}$ & $2^{\prime \prime} \times 6^{\prime \prime}$ & $2^{\prime \prime} \times 8^{\prime \prime}$ & $2^{\prime \prime} \times 10^{\prime \prime}$ & $2^{\prime \prime} \times 12^{\prime \prime}$ \\
\hline 1000 & 3.872 & 2.673 & 2.107 & 1.697 & 1.420 \\
2000 & 3.103 & 2.148 & 1.695 & 1.366 & 1.143 \\
3000 & 2.549 & 1.766 & 1.394 & 1.123 & 0.940 \\
4000 & 2.139 & 1.482 & 1.169 & 0.942 & 0.789 \\
5000 & 1.829 & 1.267 & 0.999 & 0.804 & 0.673 \\
\hline
\end{tabular}

the bending properties of the utilized wood). In all tests, the bending strength of the T-beam was always significantly higher than that of a similar bare joist.

The high variability of bending strength of the utilized wood in the experiments, along with the random locations and random sizes of knots with respect to the location of the gap between panels, explains the highly variable strengths observed in the laboratory experiments.

All the analyses performed in this paper are for the condition of constant moment throughout the length of the joist, which is the worst case scenario for nail yielding and might be a starting point for further research where other loading conditions might be considered.

The analytical and numerical analyses showed that forces in the nails are in their nonlinear region when failure loads are applied to the T-beam, according to the load-displacement relation of the nailed joint.

A method to justify an increase in strength due to NPCA has been presented. It has been demonstrated that, due to NPCA, there is a reduction in the tensile stress at the bottom of the joist even at the location of the gap in the flange. However, the strength increases are small (between 1.42 and $3.87 \%$ for two-inch thick joists with $F_{b}=1000$ psi, as shown 
in Table 1) and are not as high as the strength increases due to NPCA observed in the experiments. Nonetheless, these small increases (which can be improved by adding more nails at the ends of the joists or by considering a smaller edge distance in the nails) might be sufficient to justify a safe installation of the PV panels in many cases without any engineering certification.

Experiments and analytical analyses also suggest that, with minor changes in roof framing practices, much higher increases in strength can be achieved. These changes may be a glued-and-nailed connection between the joist and the structural sheathing (in the experiments, this type of connection was found to result in bending strengths up to $73.4 \%$ higher than the bare joist), reducing the gap between sheathing panels (as a bending strength increase of $72.3 \%$ was observed when this situation occurred in a laboratory experiment) or adding more nails at the ends of the joists (as the tensile stresses in the joist far from the gap would be further decreased).

It is recognized that the number of tests performed here was small, due to limited funding, and insufficient to produce a statistically significant data set. More tests are needed to confirm the strength increases observed in this research.

Load sharing effects of the joist-sheathing assembly should be further investigated. Furthermore, the definition of "roof failure" should be clarified. If a single joist were to crack, thus transferring a portion of its load to adjacent joists, this would well be considered sufficiently benign that it does not constitute a "roof failure." The nature of roof failures should be studied further. If roofs fail in a benign way, so that life is not endangered, it may be justified to lower the factors of safety used in design. It is worth noting that even though many roofs do not meet current design standards, over the years the number of injuries and deaths caused by collapsing residential wood roofs appears to be very low.

\section{Conflict of Interests}

The authors declare that there is no conflict of interests regarding the publication of this paper.

\section{References}

[1] H. Mi, Behavior of unblocked wood shearwalls, [MScFE thesis], University of New Brunswick, Fredericton, Cnada, 2004.

[2] E. W. Kuenzi and T. L. Wilkinson, "Composite beams-effect of adhesive or fastener rigidity," Research Paper FPL 152, Forest Products Laboratory, USDA, Forest Service, Madison, Wis, USA, 1971.

[3] W. J. McCutcheon, Method for Predicting the Stiffness of WoodJoist Floor Systems with Partial Composite Action, vol. 289 of USDA Forest Service Research Paper FPL, Forest Service, Forest Products Laboratory, United States Department of Agriculture, Madison, Wis, USA, 1977.

[4] W. J. McCutcheon, "Stiffness of framing members with partial composite action," Journal of Structural Engineering, vol. 112, no. 7, pp. 1623-1637, 1986.

[5] R. W. Wolfe and M. McCarthy, "Structural performance of light-frame roof assemblies. I: truss assemblies designed for high variability and wood failure," Research Paper FPL-RP-492, USDA, Madison, Wis, USA, 1989.

[6] R. W. Wolfe and T. LaBissoniere, "Structural performance of light-frame roof assemblies. II. Conventional truss assemblies," Research Paper FPL-RP-499, U.S. Dept. of Agriculture, Madison, Wis, USA, 1991.

[7] E. G. Thompson, M. D. Vanderbilt, and J. R. Goodman, "FEAFLO: a program for the analysis of layered wood systems," Computers \& Structures, vol. 7, no. 2, pp. 237-248, 1977.

[8] A. Polensek, "Finite element analysis of wood-stud walls," Journal of the Structural Division, vol. 102, no. 7, pp. 1317-1335, 1976.

[9] R. O. Foschi, "Structural analysis of wood floor systems," Journal of the Structural Division, vol. 108, no. 7, pp. 1557-1574, 1982.

[10] D. L. Wheat, M. D. Vanderbilt, and J. R. Goodman, "Wood floors with nonlinear nail stiffness," Journal of Structural Engineering, vol. 109, no. 5, pp. 1290-1302, 1983.

[11] W.-F. Liu and W. M. Bulleit, "Overload behavior of sheathed lumber systems," Journal of Structural Engineering, vol. 121, no. 7, pp. 1110-1118, 1995.

[12] ANSI/AF\&PA NDS-2005, National Design Specification (NDS) for Wood Construction with Commentary and Supplement, 2005.

[13] B. K. Douglas and P. Line, "System effects in wood assemblies," in Proceedings of the International Wood Engineering Conference, New Orleans, La, USA, 1996.

[14] D. V. Rosowsky and G. Yu, "Partial factor approach to repetitivemember system factors," Journal of Structural Engineering, vol. 130, no. 11, pp. 1829-1841, 2004.

[15] D. G. Rancourt, Structural behavior of wood I-Joist/OSB roof panel assemblies [M.S. thesis], University of Maine, Orono, Me, USA, 2008.

[16] T. E. McLain, Curvilinear load-slip relations in laterally loaded nailed joints [Ph.D. thesis], Colorado State University, Fort Collins, Colo USA, 1975.

[17] P. J. Pellicane, J. L. Stone, and M. D. Vanderbilt, "Generalized model for lateral load slip of nailed joints," Journal of Materials in Civil Engineering, vol. 3, no. 1, pp. 60-77, 1991.

[18] Q. Wang, Relationship between fastening properties and loaddeflection response of wood shear walls [M.S. thesis], University of New Brunswick, Fredericton, Canada, 2009. 

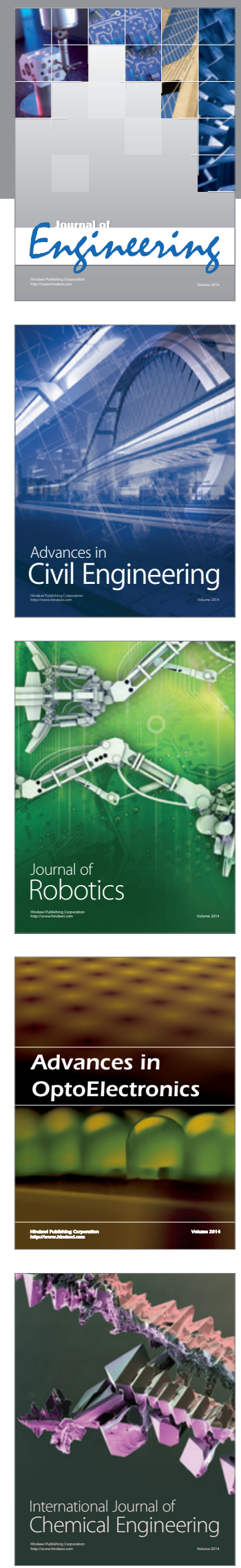

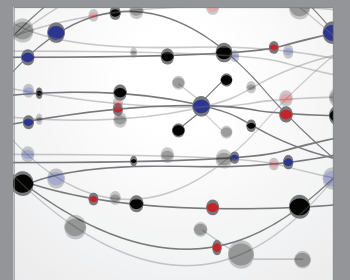

The Scientific World Journal
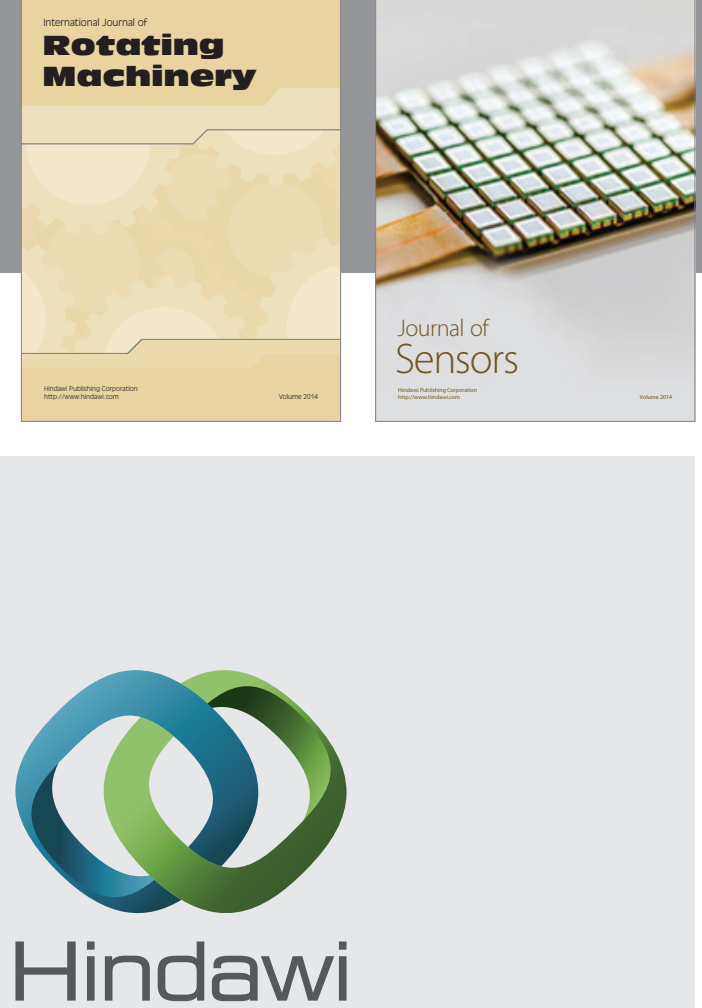

Submit your manuscripts at http://www.hindawi.com
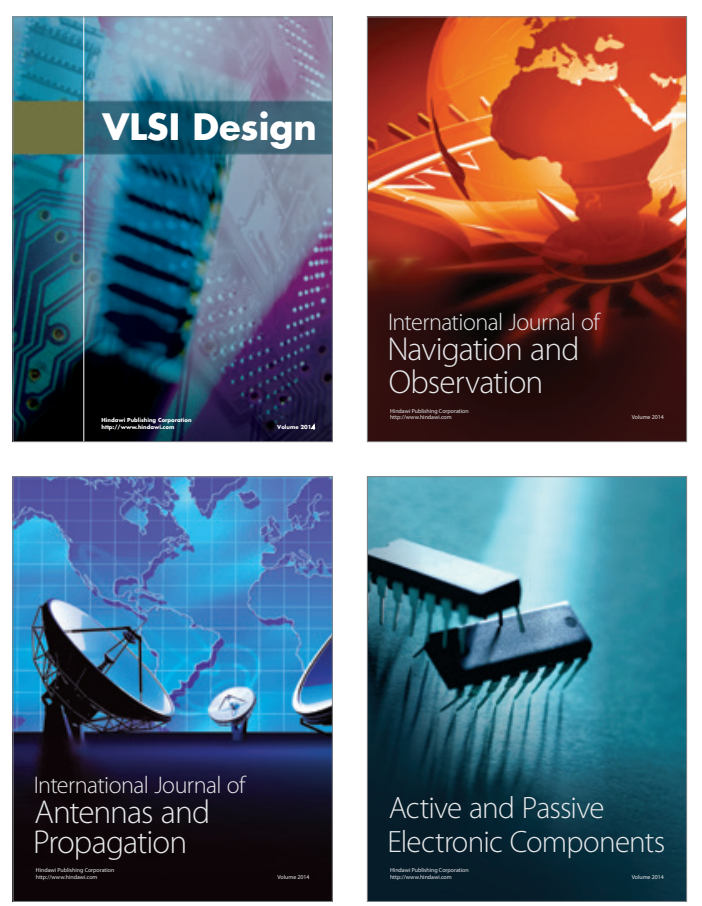
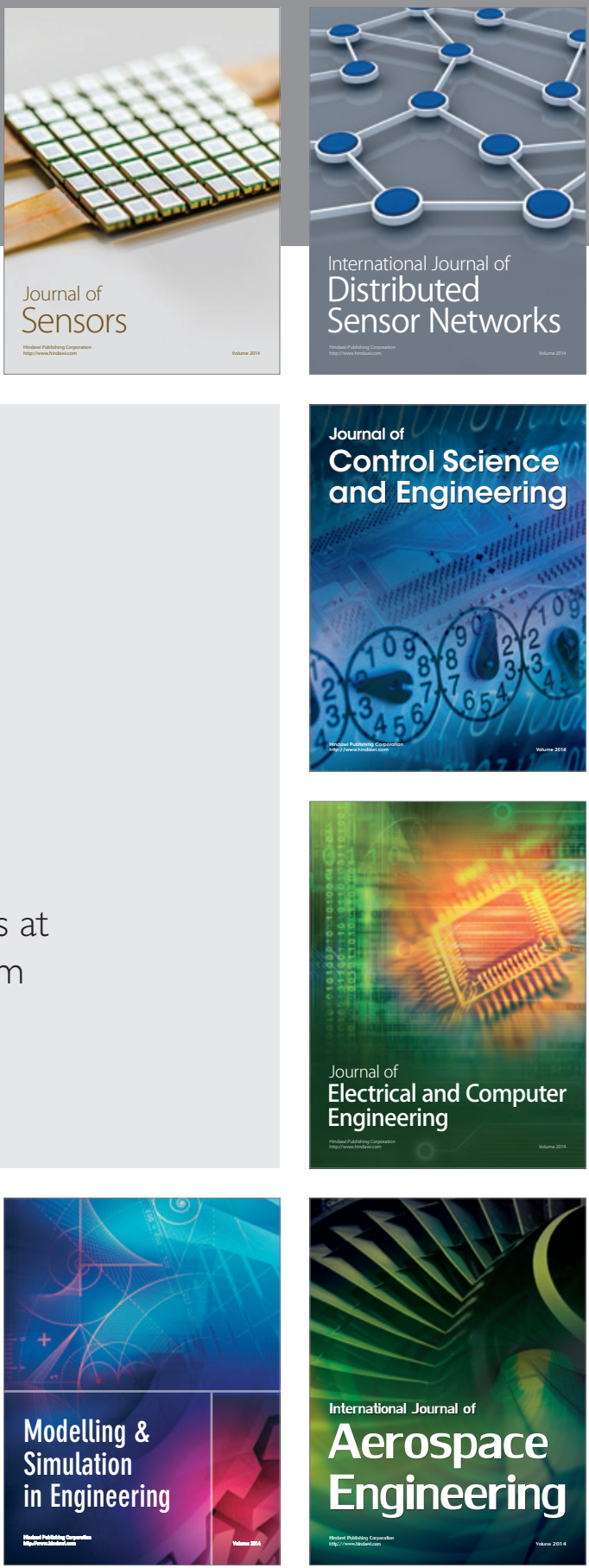

Journal of

Control Science

and Engineering
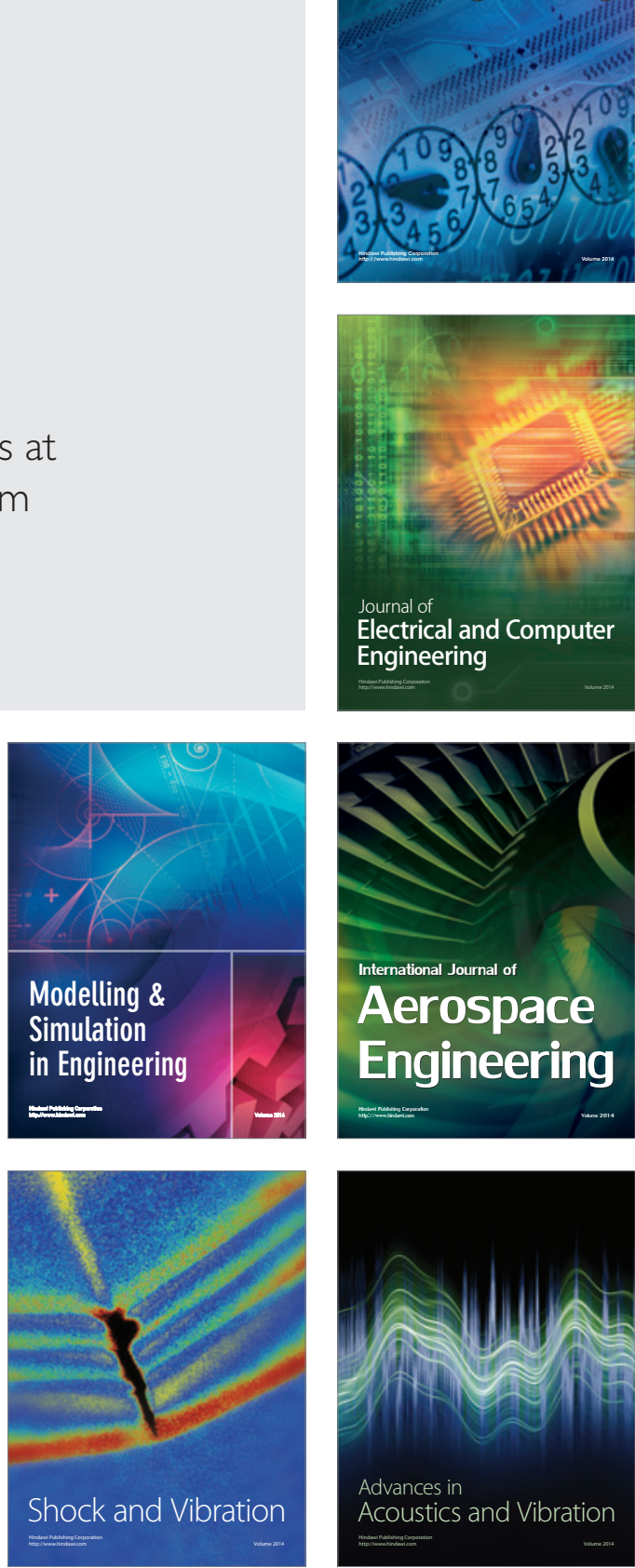